\title{
Ação de material orgânico sobre a produção e características comerciais de cultivares de alface
}

\author{
Adalberto Santi'; Marco AC Carvalho²; Ostenildo R Campos ${ }^{2}$; Amilton F da Silva ${ }^{3}$; Jefferson L de \\ Almeida $^{3}$; Stéfan Monteiro ${ }^{3}$ \\ ${ }^{1}$ UNEMAT-Campus Tangará da Serra-MT; ${ }^{2}$ UNEMAT-Campus Alta Floresta-MT; ${ }^{3}$ Acadêmico, curso de Agronomia, UNEMAT-Campus \\ Alta Floresta; adalbertosanti@unemat.br
}

\section{RESUMO}

Cultivares de alface foram avaliadas utilizando adubo orgânico contendo serragem, em cultivo protegido em Alta Floresta-MT. O delineamento experimental foi blocos casualizados em esquema fatorial com 12 tratamentos e quatro repetições, constituídos pela combinação de seis cultivares (americana: Lucy Brown e Great Lakes; crespa: Isabela e Vera; lisa: Elisa e Babá de Verão) e duas fontes de material orgânico [esterco bovino puro (100\%) e composto com pó-de-serra ( $50 \%$ de esterco bovino $+50 \%$ de pó-de-serra) na razão de $10 \mathrm{~L} \mathrm{~m}^{-2}$ ]. A presença de pó-de-serra no composto orgânico, proporcionou redução na massa fresca comercial, no comprimento do caule, na circunferência da planta, no número de folhas comerciais e no número de folhas totais, quando comparado com o tratamento contendo apenas esterco bovino curtido. Nas cultivares lisas, apesar do maior número de folhas totais e comerciais, o fato não se refletiu em maior massa comercial. A cultivar Lucy Brown conteve a maior massa fresca comercial.

Palavras-chave: Lactuca sativa L., serragem, ambiente protegido, adubo orgânico, competição.

\begin{abstract}
Effect of organic material on the production and characteristics of lettuce cultivars

Lettuce cultivars cultivated under greenhouse were evaluated with the application of cattle manure mixed to sawdust in Alta Floresta, Mato Grosso State, Brazil. The experimental design was randomized blocks in a factorial scheme with 12 treatments and four replications. The treatments consisted of combinations of six cultivars (Lucy Brown, Great Lakes, Isabela, Vera, Elisa and Babá de Verão) and two sources of organic material - cattle manure (100\%) and cattle manure mixed to sawdust (50\% manure $+50 \%$ sawdust composte) - applied at the level of $10 \mathrm{~L} \mathrm{~m}^{-2}$. Plots measured $1.2 \times 1.2 \mathrm{~m}$ with 16 plants spaced by $0.3 \mathrm{~m}$ over the useful area. Samples were constituted by the four central plants in each plot. Application of bovine manure mixed to sawdust reduced fresh mass, stem length, plant diameter, commercial leaf number and total leaf number when compared to the application of pure manure. Although the cultivars Elisa and Babá de Verão presented higher total and commercial leaf number, it did not reflect in higher commercial mass. The cultivar Lucy Brown presented the highest commercial fresh mass.
\end{abstract}

Keywords: Lactuca sativa L., saw dust, greenhouse, manure, competition.

\section{(Recebido para publicação em 17 de outubro de 2008; aceito em 24 de fevereiro de 2010) (Received on October 17, 2008; accepted on February 24, 2010)}

\begin{abstract}
A alface (Lactuca sativa L.), devido a sua importância alimentar como fonte de vitaminas e sais minerais, destaca-se entre outras hortaliças folhosas mais consumidas em todo mundo. A modernização dos segmentos locais de comercialização, evoluindo sempre em função de um consumo crescente e versátil, exige qualidade e, principalmente, regularidade do produto. Isso tem refletido diretamente nas áreas de produção que, para atender a esta nova e importante demanda do mercado, têm se modernizado com conseqüente aprimoramento técnico da mão-de-obra.

O desenvolvimento da alface é bastante influenciado pelas condições ambientais. Temperaturas acima de $20^{\circ} \mathrm{C}$ estimulam o seu pendoamento, que é acelerado à medida que a temperatura
\end{abstract}

aumenta. Dias longos associados a temperaturas elevadas, aceleram ainda mais o pendoamento, mas há variação de comportamento entre cultivares (Viggiano, 1990). O processo produtivo brasileiro passa por uma fase em que a produtividade, a eficiência, a lucratividade e a sustentabilidade são aspectos que precisam ser considerados. Nesse contexto, a obtenção de cultivares adaptadas às condições climáticas regionais, torna-se preponderante.

Por serem fontes de nutrientes e por beneficiarem propriedades físicas, químicas e biológicas do solo, os adubos orgânicos são amplamente recomendados para as hortaliças (Kiehl, 1985; Sonnenberg, 1985; Comissão, 1999), em decorrência da maior disponibilidade de nutrientes, do aumento do $\mathrm{pH}$, do aumento da atividade de macro e microorganismos, bem como pelos efeitos indiretos da melhoria de propriedades físicas, químicas e biológicas do solo (Mazur et al., 1983; Kiehl, 1985; Siqueira, 1988). Entretanto, o valor fertilizante do composto depende do material utilizado como matéria-prima (Miyasaka et al., 1997).

A atuação conjunta desse e de inúmeros outros efeitos resulta, em muitos casos, em produtividades de alface que podem superar as obtidas com adubos minerais (Hartrath, 1986).

A grande maioria dos trabalhos disponíveis refere-se ao uso de estercos, resíduos líquidos e restos vegetais, reportando seus efeitos como melhoradores do solo e fornecedores de nutrientes. Embora parte dessa informação possa 
ser extrapolada e assumida como válida no que diz respeito ao uso de compostos, estes têm uma dinâmica no solo bastante diversa dos materiais em estado natural, por ser uma matéria orgânica decomposta e estabilizada (Kiehl, 1985).

Com relação à alface, tem-se observado que os produtores utilizam geralmente um sistema de produção, com uso excessivo de fertilizantes minerais. Uma das alternativas para contornar este tipo de problema seria o uso de compostos orgânicos. Tendo em vista a região norte mato-grossense ser grande pólo madeireiro e pecuário, verifica-se uma fácil disponibilidade de matérias-primas para a confecção de compostos orgânicos de qualidade, tais como serragem, esterco de curral e capineiras. As altas produtividades obtidas com uso intensivo de adubos minerais têm sido questionadas nos últimos anos, devido aos aspectos relacionados à sustentabilidade do sistema de produção (Santos et al., 1994). Pelo exposto e pelo alto custo de fertilizantes minerais, cultiva-se hortaliças com adubos orgânicos de várias origens, visando melhorar as propriedades físicas e químicas do solo (Costa, 1994).

Neste sentido o adubo orgânico adicionado ao solo tem efeito imediato e ainda residual por meio de um processo mais lento de decomposição e liberação de nutrientes (Vidigal et al., 1997). O presente trabalho teve como objetivo avaliar características produtivas de seis cultivares de alface, utilizando adubo orgânico contendo serragem, cultivadas em ambiente protegido no município de Alta Floresta-MT.

\section{MATERIAL E MÉTODOS}

O experimento foi conduzido em ambiente protegido, na Universidade do Estado de Mato Grosso, no município de Alta Floresta-MT, tendo como coordenadas geográficas $09^{\circ} 53^{\prime} 02^{\prime \prime}$ latitude sul, 56 ${ }^{\circ} 14$ '38' longitude oeste Gr. e, altitude de $290 \mathrm{~m}$.

O solo é classificado como Latossolo Vermelho-Amarelo distrófico (LVAd) típico argiloso, A moderado, hipodistrófico, caulinítico, compactado, muito profundo, moderadamente ácido. A temperatura média anual é de $24^{\circ} \mathrm{C}$.
A área de pesquisa foi constituída por uma estrutura de proteção, modelo túnel alto, com 21,0 m de comprimento; 5,20 $\mathrm{m}$ de largura, contendo 2,30 $\mathrm{m}$ de pé-direito e coberta com película de polietileno transparente de baixa densidade aditivada anti UV de 100 micras de espessura.

O delineamento experimental foi blocos casualizados em esquema fatorial $6 \times 2$ com tratamentos resultantes da combinação de seis cultivares (americana: Lucy Brown e Great Lakes; crespa: Isabela e Vera; lisa: Elisa e Babá de Verão) e duas fontes de matéria orgânica, esterco bovino e combinação de esterco com pó-de-serra ( $50 \%$ de esterco bovino + 50\% de pó-de-serra) na razão de 10 $\mathrm{L} \mathrm{m}^{-2}$, e quatro repetições. A adubação química básica constituiu-se de $150 \mathrm{~kg}$ de $\mathrm{N}, 400 \mathrm{~kg}$ de $\mathrm{P}_{2} \mathrm{O}_{5}$ e $90 \mathrm{~kg}$ de $\mathrm{K}_{2} \mathrm{O}$, sendo que o $\mathrm{N}$ e o $\mathrm{K}$ foram utilizados de forma parcelada, segundo Fontes (1999).

As mudas foram preparadas em bandejas de poliestireno (isopor) contendo 144 células, preenchidas com substrato comercial e postas em um ambiente de produção de mudas. O transplante das mudas para a área experimental foi realizado quando as mesmas atingiram quatro folhas definitivas.

As parcelas foram de 1,2 x 1,2 m com 16 plantas em espaçamento de $0,3 \times 0,3 \mathrm{~m}$, sendo que na área útil analisaram-se as quatro plantas centrais de cada parcela.

Foram avaliadas as variáveis: massa fresca total (as plantas foram cortadas rente ao solo e medidas suas massas em balança analítica, através da pesagem do número total de folhas de cada planta analisada), massa fresca comercial (referente à estimativa da massa, sem a presença das folhas com danos que prejudicam visualmente a comercialização da planta), circunferência da planta (obtida após retirada das folhas externas não comerciais, medindo-se através de régua o diâmetro da circunferência de uma extremidade a outra da planta), comprimento e diâmetro do caule (expressos após a retirada de todas as folhas, medindo-se o comprimento do caule e seu diâmetro através de paquímetro) e contagem do número total e comercial de folhas (expresso pelo número total de folhas e número de folhas sem danos visuais respectivamente).

Os dados obtidos foram submetidos à análise de variância, sendo as médias comparadas pelo teste Tukey, em 5\% de probabilidade.

\section{RESULTADOS E DISCUSSÃO}

Houve interação significativa entre as fontes de variação adubos orgânicos (AO) e cultivares (C) de alface, apenas para a massa fresca total e diâmetro do caule, o que indica que em presença do adubo orgânico, isoladamente, ou com a adição de serragem, as cultivares não revelaram variação quanto às demais características agronômicas avaliadas. No entanto, o tratamento adubo orgânico expressou efeitos significativos para as

Tabela 1. Desdobramento da interação significativa entre adubo orgânico e cultivares de alface para massa fresca total (g/planta) (parametrization of the significant interaction between organic fertilization and lettuce cultivars for total fresh mass). Alta Floresta, UNEMAT, 2006.

\begin{tabular}{lcc}
\hline \multirow{2}{*}{ Cultivar } & \multicolumn{2}{c}{ Adubo orgânico } \\
\cline { 2 - 3 } & Esterco & Esterco + serragem \\
\hline Lucy Brown & $400,12 \mathrm{~A} \mathrm{a}$ & $322,25 \mathrm{~B} \mathrm{a}$ \\
Great Lakes & $210,44 \mathrm{~A} \mathrm{~b}$ & $194,47 \mathrm{~A} \mathrm{bc}$ \\
Elisa & $157,05 \mathrm{~A} \mathrm{~b}$ & $119,47 \mathrm{~A} \mathrm{c}$ \\
Babá de Verão & $174,29 \mathrm{~A} \mathrm{~b}$ & $116,61 \mathrm{~A} \mathrm{c}$ \\
Isabela & $221,62 \mathrm{~A} \mathrm{~b}$ & $231,22 \mathrm{~A} \mathrm{~b}$ \\
Vera & $242,82 \mathrm{~A} \mathrm{~b}$ & $218,73 \mathrm{~A} \mathrm{~b}$ \\
\hline Médias &
\end{tabular}

Médias seguidas de mesma letra, maiúsculas nas linhas e minúscula na coluna não diferem entre si, teste Tukey, $\mathrm{p}<0,05$ (means followed by the same capital letter in the rows and small letter in the columns did not differ from each other by Tukey's test $(p<0,05))$. 
Tabela 2. Desdobramento da interação significativa entre adubo orgânico e cultivares de alface para diâmetro do caule $(\mathrm{mm})$ (parametrization of the significant interaction between organic fertilization and lettuce cultivars for stem diameter). Alta Floresta, UNEMAT, 2006.

\begin{tabular}{lcc}
\hline \multirow{2}{*}{ Cultivar } & \multicolumn{2}{c}{ Adubo orgânico } \\
\cline { 2 - 3 } & Esterco & Esterco + serragem \\
\hline Lucy Brown & $22,98 \mathrm{~A} \mathrm{~b}$ & $22,23 \mathrm{~A} \mathrm{a}$ \\
Great Lakes & $16,95 \mathrm{~A} \mathrm{~b}$ & $18,58 \mathrm{~A} \mathrm{a}$ \\
Elisa & $21,85 \mathrm{~A} \mathrm{~b}$ & $18,27 \mathrm{~A} \mathrm{a}$ \\
Babá de Verão & $33,18 \mathrm{~A} \mathrm{a}$ & $20,64 \mathrm{~B} \mathrm{a}$ \\
Isabela & $18,25 \mathrm{~A} \mathrm{~b}$ & $20,18 \mathrm{~A} \mathrm{a}$ \\
Vera & $19,10 \mathrm{~A} \mathrm{~b}$ & $18,55 \mathrm{~A} \mathrm{a}$ \\
\hline
\end{tabular}

Médias seguidas de mesma letra, maiúsculas nas linhas e minúscula na coluna não diferem entre si, teste Tukey, $\mathrm{p}<0,05$ (means followed by the same capital letter in the rows and small letter in the columns did not differ from each other by Tukey's test $(p<0,05)$.

características avaliadas, exceto para diâmetro do caule.

O desdobramento da interação cultivares versus adubo orgânico (Tabela 1) para a variável massa fresca total, quando se analisa cultivares em relação ao adubo orgânico, revelou superioridade da cultivar Lucy Brown para o tratamento em que se utilizou apenas esterco ou esterco com serragem. Para esta sendo fato ainda que apenas o uso de esterco foi superior ao composto esterco + serragem.

Analisando a variável diâmetro do caule no desdobramento de cultivares dentro de adubo orgânico (Tabela 2), verificam-se semelhanças tanto para o tratamento em que se utilizou do esterco + serragem quanto para o tratamento que conteve apenas o esterco, exceto para a cultivar Babá de Verão, que demonstrou

Tabela 3. Características ${ }^{1}$ avaliadas em plantas de alface em função de cultivares (lettuce characteristics ${ }^{1}$ evaluated in function of cultivars). Alta Floresta, UNEMAT, 2006.

\begin{tabular}{llllll}
\hline Cultivar & $\begin{array}{c}\text { MFC } \\
\left.\mathbf{( g ~ p l a n t a ~}^{-1}\right)\end{array}$ & $\begin{array}{c}\text { CC } \\
(\mathbf{m m})\end{array}$ & $\mathbf{C P}(\mathbf{c m})$ & NFT & NFC \\
\hline Lucy Brown & $315,27 \mathrm{a}$ & $58,02 \mathrm{abc}$ & $31,86 \mathrm{a}$ & $22,15 \mathrm{~b}$ & $19,44 \mathrm{c}$ \\
Great Lakes & $183,61 \mathrm{bc}$ & $40,19 \mathrm{c}$ & $28,56 \mathrm{ab}$ & $15,59 \mathrm{c}$ & $13,59 \mathrm{~d}$ \\
Elisa & $123,86 \mathrm{~d}$ & $51,79 \mathrm{bc}$ & $21,44 \mathrm{~d}$ & $34,96 \mathrm{a}$ & $30,75 \mathrm{a}$ \\
Babá de Verão & $127,04 \mathrm{~cd}$ & $53,24 \mathrm{bc}$ & $22,93 \mathrm{~cd}$ & $31,01 \mathrm{a}$ & $26,51 \mathrm{~b}$ \\
Isabela & $200,31 \mathrm{~b}$ & $67,55 \mathrm{ab}$ & $26,97 \mathrm{~b}$ & $20,77 \mathrm{~b}$ & $17,67 \mathrm{c}$ \\
Vera & $200,34 \mathrm{~b}$ & $72,72 \mathrm{a}$ & $26,80 \mathrm{bc}$ & $23,32 \mathrm{~b}$ & $19,92 \mathrm{c}$ \\
\hline
\end{tabular}

Médias seguidas pela mesma letra na coluna não diferem entre si, teste de Tukey, $p<0,05$ (means followed by the same letter in the column did not differ from each other by Tukey's test, $\mathrm{p}<0,05)$. ${ }^{1} \mathrm{MFC}$ : massa fresca comercial; $\mathrm{CC}=$ comprimento do caule; $\mathrm{CP}=$ circunferência da planta; $\mathrm{NFT}=$ número de folhas totais; $\mathrm{NFC}=$ número de folhas comerciais. $(\mathrm{MFC}=$ commercial fresh mass; $\mathrm{CC}=$ stem length; $\mathrm{CP}=$ plant circumference; $\mathrm{NFT}=$ total number of leaves; $\mathrm{NFC}=$ commercial number of leaves). fresca comercial $(205,78 \mathrm{~g} /$ planta $)$, comprimento do caule $(63,68 \mathrm{~mm})$, circunferência da planta $(27,41 \mathrm{~cm})$, número de folhas totais $(25,69)$ e número de folhas comerciais $(22,37)$.

As relações $\mathrm{C} / \mathrm{N}$ entre os adubos orgânicos são diferentes principalmente se considerarmos esterco e esterco+serragem de madeira. Para este último com maior relação $\mathrm{C} / \mathrm{N}$, a liberação de nutrientes é mais lenta para as plantas de alface. Esta inferência pode ser reforçada pelo fato de que alguns compostos possuem estruturas de difícil decomposição pela população microbiana do solo, tais como a celulose e a lignina, presentes na serragem de madeira (Villas Boas et al., 2004). Além disso, a decomposição de materiais provenientes de madeira, resulta em liberação para o meio de resinas, terpenóides e substâncias fenólicas, dentre outros compostos, que podem causar injúrias nas plantas (Kiehl, 1985).

Baseado nos dados contidos na Tabela 3, a cultivar Lucy Brown revelou os maiores valores para massa fresca comercial e circunferência da planta sendo que a Great Lakes foi similar à cultivar Lucy Brown quanto à circunferência da planta. Já para comprimento do caule, as cultivares Vera, Isabela e Lucy Brown expressaram os maiores valores. A cultivar Elisa revelou os maiores valores, para o número de folhas totais e comerciais, bem como a Babá de Verão expressou semelhança quanto ao número de folhas totais à cultivar Elisa.

Os resultados ratificam que o uso de esterco bovino isoladamente produziu melhores resultados para as características avaliadas, com exceção da massa fresca total e diâmetro de caule, em que houve semelhança em relação ao composto de esterco + serragem. A cultivar Lucy Brown destacou-se comparativamente às demais.

\section{REFERÊNCIAS}

COSTA CA. 1994. Crescimento e teores de sódio e de metais pesados na alface e na cenoura adubadas com composto orgânico de lixo urbano. Viçosa: UFV 89p. (Tese mestrado).

FONTES PCR. 1999. Alface. In: RIBEIRO AC; GUIMARÃES PTG; ALVAREZ VH (Eds) Recomendações para o uso de corretivos e fertilizantes em Minas Gerais. $5^{\mathrm{a}}$ Aproximação. 
Lavras: SBCS. p-177.

HARTRATH H. 1986. Manuring of butterhead lettuce. Horticultural Abstract 56: 7739.

KIEHL EJ. 1985. Fertilizantes orgânicos. 1. ed. São Paulo: Agronômica Ceres. 492p.

MAZUR N; VELLOSO ACX; SANTOS GA. 1983. Efeito do composto de resíduo urbano no pH e alumínio trocável em solo ácido. Revista brasileira de Ciência do Solo 7: 157-159.

MIYASAKA S; NAKAMURA Y; OKAMOTO

H. 1997. Agricultura natural. 2. ed. Cuiabá: SEBRAE/MT, 73p. (Coleção agroindústria).
SANTOS RHS; CASALI VWD; CONDÉ AR; MIRANDA LCG. 1994. Qualidade de alface cultivada com composto orgânico. Horticultura Brasileira 12: 29-32.

SIQUEIRA JO. 1988. Biotecnologia do solo: fundamentos e perspectivas. Lavras: MEC/ ABEAS, 235p.

SONNENBERG PE. 1985. Olericultura especial. Primeira Parte. 5. ed. Goiânia: UFG, 189p.

VIDIGAL SM; SEDIYAMA MAN; GARCIA NCP; MATOS AT. 1997. Produção de alface cultivada com diferentes compostos orgânicos e dejetos suínos. Horticultura Brasileira 15: 35-39.

VILLAS BÔAS RL; PASSOS JC; FERNANDES M; BULL LT; CEZAR, VRS; GOTO R. 2004. Efeito de doses e tipos de compostos orgânicos na produção de alface em dois solos sob ambiente protegido. Horticultura Brasileira 22: $28-34$.

VIGGIANO J. 1990. Produção de sementes de alface. In: CASTELLANE PD. Produção de Sementes de Hortaliças. Jaboticabal: FCAVFUNEP, p.1-15. 